\title{
Haloperidol Adjunct With Morphine on Postoperative Pain Management in Opioid-Addicted Patients Undergoing Orthopedic Surgery
}

\author{
Asif Parviz Kazemi, Tahere Jowkar, ${ }^{2, *}$ Afshin Amini, ${ }^{1}$ and Seyed Taghi Heydari ${ }^{3}$ \\ ${ }^{1}$ Department of Anesthesiology, Shiraz University of Medical Sciences, Shiraz, IR Iran \\ 2 Faculty of Medicine, Shiraz University of Medical Sciences, Shiraz, IR Iran \\ ${ }^{3}$ Health Policy Research Center, Shiraz University of Medical Sciences, Shiraz, IR Iran \\ *Corresponding Author: Tahere Jowkar, Faculty of Medicine, Shiraz University of Medical Sciences, Shiraz, IR Iran. Tel:+98-9173072965, Fax:+98-7132318072, E-mail: tjowkar@yahoo.co.uk
}

Received 2015 June 10; Revised 2015 August 23; Accepted 2015 August 26.

\begin{abstract}
Background: Postoperative pain in addicted patients is important because they are opioid tolerant, they have abnormal pain sensitivity and psychological disorders. Many modalities and combination of medications have been used to reduce the suffering of addicted patients' postoperative pain. There has been some evidence for the use of antipsychotics for such pain control.

Objectives: The aim of this study was to compare the effect of morphine versus morphine/haloperidol on postoperative pain management in opioid-addicted patients undergoing orthopedic surgery.

Patients and Methods: In this randomized double-blinded placebo-controlled trial, 101 addicted patients were divided randomly into two groups. For pain intensity, the categorical scale was marked by asking the patient at time zero in the recovery unit. The patients received $0.1 \mathrm{mg} / \mathrm{kg}$ morphine with either $20 \mathrm{mg}$ haloperidol or $4 \mathrm{~mL}$ normal saline in the first episode of pain, according to the study groups. Pain ratings were obtained at 30-minute intervals till two hours. Pain scores were measured by the summation of numbers equal to pain severity in the categorical scale. The total morphine dosage was also assessed in the study.

Results: The trend of decrease in the pain scores between the placebo and haloperidol groups was significant $(\mathrm{P}<0.001)$ with higher slope in the haloperidol group. The trend of decrease in morphine consumption between the groups was significant $(\mathrm{P}<0.001)$ with higher slope in the haloperidol group. In the placebo group, at hour two, 45 patients (90\%) were pain-free, whereas in the haloperidol group, 51 patients $(100 \%)$ were pain-free $(\mathrm{P}=0.027)$. The total morphine dosages used in the two groups had a statistically significant difference $(\mathrm{P}$ $<0.001)$.

Conclusions: Haloperidol together with morphine is beneficial in postoperative pain management in opium-addicted patients.
\end{abstract}

Keywords: Analgesia, Haloperidol, Morphine, Opium Pain Measurement, Pain Postoperative

\section{Background}

Postoperative pain management is one of the important issues in the field of pain control (1). Postoperative pain may be difficult to manage in opium-addicted patients because the standard approaches used for assessment and therapies in opioid-naive patients are inadequate for addicted patients (2). They need maintenance of a basal opioid requirement and control of incisional pain. Opium addict patients are opioid tolerant. They have concomitant psychological disorders and abnormal pain sensitivity (3). Although opioids have been used for a long time as postoperative analgesia, the current trend is shifting to non-opioid analgesia (4-6), multimodal analgesia (7), and regional nerve blocks (8). In 1957, haloperidol, the first butyrophenone, was synthesized. Since then, antipsychotics showed analgesic effects in acute and chronic painful situations such as cancer pain, chronic headache, post-herpetic neuralgia, and chronic facial pain.

Haloperidol, a dopamine $\mathrm{D}_{2}$ receptor antagonist, is successfully used in dementia, nonspecific delirium, and an- tiemetic prophylaxis for postoperative nausea and vomiting. It is a substitute derivative of meperidine (9). It binds competitively to brain opioid receptors in vitro $(10,11)$ and is used for withdrawal symptoms in opioid-addicted rats $(12,13)$. These findings in animal studies strongly support its analgesic properties as well as evidences got from human clinical trials.

\section{Objectives}

In this randomized trial, we aimed to evaluate the analgesic potency of haloperidol in combination with morphine for postoperative pain control in addicted patients.

\section{Patients and Methods}

\subsection{Patients}

In this study, we selected 101 male opium addicts (those using inhaled opium at least three days a week for at least one month), aged 20 to 50 years, undergoing femoral or 
tibial fracture fixation in Chamran Hospital, Shiraz, Iran, during 2008 - 2009, according to the ranking system of American Society of Anesthesiologist (ASA) with physical state class I and II. Because of the patients' cultural habits and our inability to control their use of opium or change the opioid to equianalgesic dosing, the patients were permitted to have their routine use of opium until the operation. The exclusion criteria were patients with psychological disorders or using related medications, renal and hepatic disorder, benign prostate hyperplasia, glaucoma, and any history of reaction to haloperidol or extrapyramidal syndrome. Patients unable to use their routine opium in the hospital before the operation and those with no pain in the recovery room were also excluded from the study.

The patients were randomly allocated through sequential simple sampling method and were divided into haloperidol and placebo groups. Patients with odd and even file numbers were considered as haloperidol and placebo groups, respectively. The study was double-blinded, i.e. the patients, the researcher filling the forms and the nurse giving the medications were all blind to the study groups. The medications were prepared and labeled by a staff member not involved in the study. Fifty one syringes, labeled "A", were filled with $4 \mathrm{~mL}$ haloperidol (20 $\mathrm{mg}$ ) while 50 syringes, labeled "B", were filled with $4 \mathrm{~mL}$ normal saline. In the first episode of pain in the recovery unit, patients with odd file numbers received syringe " $\mathrm{A}$ " and those with even file numbers received syringe "B".

\subsection{Study Protocol}

A pilot study including 18 patients was performed to determine the best effective dose of haloperidol in opium-addicted patients. The mean pain scores were evaluated at 30 minutes and one hour after entering the recovery unit.

The mean pain scores at 30 minutes after entering the recovery unit were 13.2, 13.2, 7.0 and 2.75 for $5 \mathrm{mg}, 10 \mathrm{mg}$, $15 \mathrm{mg}$ and $20 \mathrm{mg}$ haloperidol, respectively. The mean pain scores at one hour after entering the recovery unit were $13.2,11.2,9.75$ and 2.5 for $5 \mathrm{mg}, 10 \mathrm{mg}, 15 \mathrm{mg}$ and $20 \mathrm{mg}$ haloperidol, respectively. The results showed that the best pain relief was achieved by $20 \mathrm{mg}$ haloperidol dose for both 30 minutes and one hour after entering the recovery unit. Raft et al. also suggested in that "haloperidol in larger doses had analgesic properties, which is generally in doses above $15 \mathrm{mg}$ " (14). Finally, $20 \mathrm{mg}$ haloperidol was used for its analgesic effects in this study.

A day prior to the operation, the patients were visited and after explaining the study to them, informed consent was obtained from each patient. The study protocol was according to the ethical guidelines of the 1975 declaration of Helsinki. Anesthetic drugs for the induction of anesthesia were midazolam $0.03 \mathrm{mg} / \mathrm{kg}$, morphine $0.2 \mathrm{mg}$ / $\mathrm{kg}$, pentothal $5 \mathrm{mg} / \mathrm{kg}$, and cisatracurium $0.15 \mathrm{mg} / \mathrm{kg}$, to facilitate tracheal intubation. Anesthesia was maintained with a mixture of oxygen and nitrous-oxide $50 \%$ and isoflurane with minimum alveolar concentration (MAC) between $1-1.5$. Any patient with pain during the operation according to his symptoms had $0.25 \mu \mathrm{g}$ remifentanil with pump infusion. In the recovery unit, pain intensity was measured with the categorical scale, a horizontal line with anchors of 'no pain', 'mild', 'moderate', 'severe' and 'worst possible pain'. Pain scores were numbered 'o', '1', ' 2 ', ' 3 ' and ' 4 ' equal to the anchors in the scale. In the first episode of pain, the scales were marked by the patients (time zero) and the patients received $0.1 \mathrm{mg} / \mathrm{kg}$ morphine plus either $20 \mathrm{mg}$ haloperidol (Halodic, Caspain Tamin Inc. Iran) or $4 \mathrm{~mL}$ normal saline intravenously according to the study groups. Thereafter, pain ratings were obtained at 30-minute intervals till two hours while the patient was in the recovery unit.

According to the pain severity, patients with next episodes of 'mild' to 'moderate' pain received $0.07 \mathrm{mg} / \mathrm{kg}$ morphine and those with 'severe' or 'worst possible' pain received $0.1 \mathrm{mg} / \mathrm{kg}$ morphine additionally. The total morphine dosage was also considered in the evaluation of patients' pain control.

\subsection{Statistical Analysis}

Statistical analysis was performed with statistical package for the social sciences (SPSS) version 15.0 software (SPSS, Chicago, IL, USA). Repeated measures were performed to determine the trend of pain scores and morphine consumption between the groups. The percentages of pain-free patients at hour two were compared with Fisher's Exact test. The total morphine dosage used was compared with independent two-sample t-test. Data was reported as Means \pm Standard Deviation. Two-tailed $P$ values less than 0.05 were considered statistically significant.

\section{Results}

The mean of age and weight was not significant between the two groups $(P>0.05$, Table 1$)$. The pain scores at time zero were not significantly different between the groups $(\mathrm{P}=0.313)$. The trend of decrease in pain scores between the groups was significant $(\mathrm{P}<0.001)$ with higher slope in the haloperidol group (Figure 1). The trend of decrease in morphine consumption between the groups was significant $(\mathrm{P}<0.001)$ with higher slope in the haloperidol group (Figure 2). At hour two, in the haloperidol group, 51 patients (100\%) were pain-free whereas in the placebo group, 45 patients (90\%) were pain-free despite trying for tight pain control with additional morphine doses $(\mathrm{P}=$ 0.027). The mean of total morphine doses in the haloperidol group (7.62 $\mathrm{mg} \pm 2.09$ ) and the placebo group (15.61 $\mathrm{mg} \pm 3.86)$ had a significant statistical difference $(\mathrm{P}<$ 0.001 ) and the placebo group received about two times more morphine compared with the haloperidol group. None of the patients showed psychomotor or extra pyramidal complications attributed to the use of haloperidol. 
Table 1. The Comparison of Mean Age and Weight Between the Two Study Groups

\begin{tabular}{lccc}
\hline Group & No. & Mean \pm SD & P Value \\
\hline Age & & & 0.823 \\
\hline Haloperidol,20 mg & 51 & $37.16 \pm 8.24$ & \\
\hline Placebo & 50 & $37.54 \pm 8.87$ & \\
Weight & & & 0.950 \\
\hline Haloperidol,20 mg & 51 & $66.47 \pm 10.69$ & \\
\hline Placebo & 50 & $66.6 \pm 9.97$ & \\
\hline
\end{tabular}

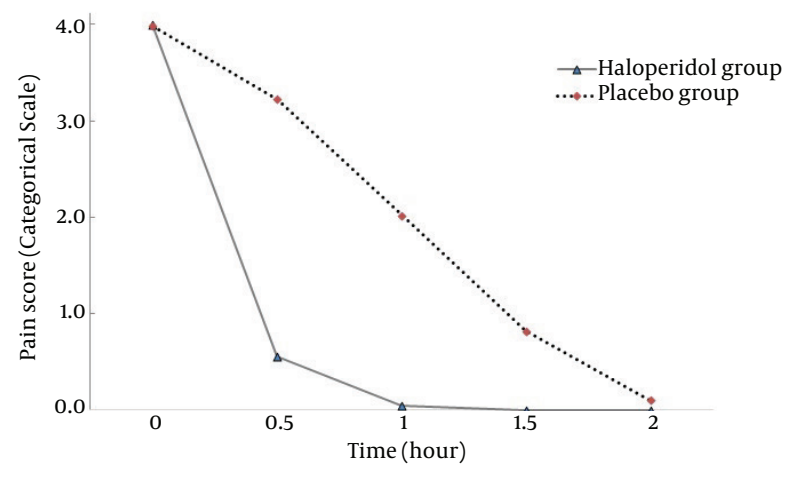

Figure 1. The Trend of Pain Score During the Postoperative Time

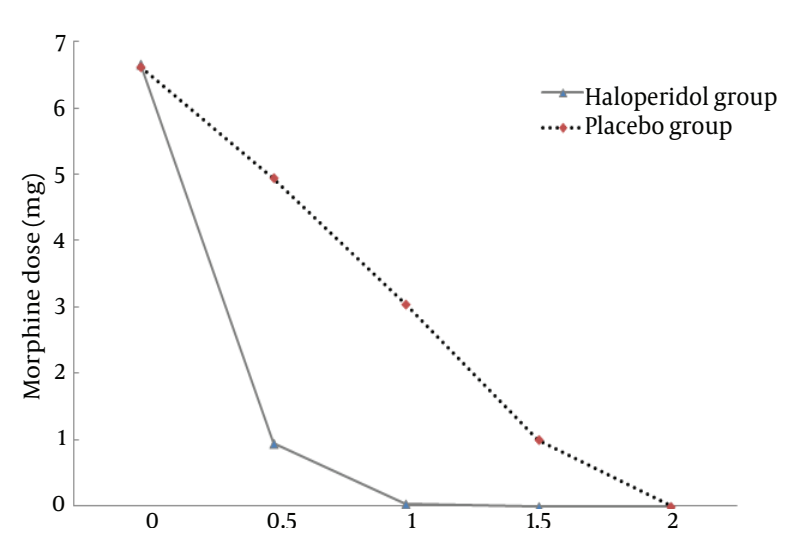

Figure 2. The Trend of Morphine Dose Consumption During the Postoperative Time

\section{Discussion}

A large number of opium-addicted patients are presenting for surgeries. They experience increased postoperative pain and greater postoperative opioid consumption (3). Achieving adequate pain control in these patients can be challenging, because commonly-used strategies for alleviating postoperative pain have diminished effectiveness.

The role of classic antipsychotics as adjuvant analgesics has been a subject of a longstanding controversy. How- ever, as the time passes, the evidences support the effects of antipsychotics in the treatment of pain. Fishbain et al. conducted an evidence-based review on the potential effectiveness of atypical neuroleptics for the treatment of pain. Of the 10 studies, all except for one (90\%) indicated that the atypicals had analgesic effects (15). Seidel et al. performed a review on randomized controlled trials published in Cochrane Database of Systematic Review to assess the analgesic efficacy of antipsychotics in acute or chronic pain. From 11 randomized clinical trials, six found beneficial effects of antipsychotics in the treatment of acute and chronic pain. The authors concluded antipsychotics to be used as an add-on therapy in the treatment of painful conditions (16).

In 1957, haloperidol, a dopamine $\mathrm{D}_{2}$ receptor antagonist neuroleptic was developed as a substitute derivative of meperidine, a phenylpiperidine analgesic (17). From then on, basic studies found the analgesic effects for haloperidol. Some studies suggested that haloperidol analgesic effect is seen when used in combination with morphine (18). Head et al. found that haloperidol pretreatment in rats caused an enhancement in morphine analgesia. No analgesia was present in haloperidol-treated rats which were not given morphine (19). Rooney et al. suggested that $\mathrm{D}_{2}$ receptor antagonists appear to potentate opioid-induced antinociception in laboratory animals. The authors said that this may not arise only from their dopamine antagonist activity and the combination of dopamine $\mathrm{D}_{2}$ receptor antagonists with opioids enhanced the analgesic effect of opioids (20). This finding makes haloperidol suitable for postoperative pain, where opioids are commonly used. We considered this add-on therapy as a strong point in our study. There are a number of studies in opioid addict animals showing that haloperidol suppressed opioid withdrawal syndromes. Karkalas et al. formed two studies both showing haloperidol to suppress the withdrawal symptoms in addicted animals and to reduce the self-administration of morphine in addicted rats $(21,22)$. Lal et al. also performed two studies with similar results $(12,13)$. This means less morphine consumption in opioid addicts when haloperidol is used. This is another important factor considered in our study for opioid addict patients.

Evidences from human studies also support the analgesic role of haloperidol. Saarne directed 1163 patients with $5 \mathrm{mg}$ haloperidol as premedication before surgery. In $94 \%$ of the patients, the amount of postoperative analgesics required was significantly reduced (23). In another study, Maltbie et al. reported 10 patients involved with various intractable pain syndromes, in which the administration of haloperidol either eliminated or significantly reduced the need for narcotic analgesics (24). Clay et al. (10) and Creese et al. (11) explained the pharmacological basis for this effect by opiate receptor binding sites for haloperidol, which demonstrates that haloperidol has a mild narcotic agonist activity $(10,11)$.

Raft et al. focused on 12 subjects with chronic facial 
pain who failed to respond to a variety of modalities of therapy. They found that adding haloperidol to relaxation therapy resulted in better responses (14). Judkins et al. (25) selected 34 patients to evaluate the effect of haloperidol on postoperative analgesia in two doses as a premedication compared with a placebo. They found no significant difference between the groups in terms of analgesic requirements or the degree of pain relief. In their study, 5 and $10 \mathrm{mg}$ haloperidol were used and the visual analogue scale for analgesia was completed between 24 and 72 hours after the operation. Because of the studies that support the analgesic effect of haloperidol, the authors suggested the analgesic effects of haloperidol to be time- and dose-related and short-lived. They suggested studies with increased dose or closer administration of haloperidol to evaluate its analgesic effect, both of which were considered in our study (25).

Honkaniemi et al. carried out a randomized placebocontrolled study with 40 patients to assess the efficacy of haloperidol in the treatment of acute migraine headache. A significant pain relief was achieved in $80 \%$ of the patients treated with $5 \mathrm{mg}$ haloperidol, whereas only three patients responded to placebo $(\mathrm{P}<0.001)$. The study showed that haloperidol was very effective on relieving migraine-associated pain (26). Hagelberg et al. $(27,28)$ found some preclinical theoretical evidence indicating that neuroleptics active at dopamine $\mathrm{D}_{2}$ receptors such as haloperidol should have analgesic effects. They selected 19 volunteers for a dopamine $\mathrm{D}_{2}$ receptor positron emission tomography study. They found an inverse correlation of pain threshold with $\mathrm{D}_{2}$ binding potential in the right putamen. Individuals with only few available $\mathrm{D}_{2}$ receptors in the forebrain are likely to have a tonic level of pain suppression $(27,28)$.

Gear et al. conducted a study, in which before the surgical extraction of impacted mandibular third molar teeth, patients received $1 \mathrm{mg}$ haloperidol, $10 \mathrm{mg}$ chlorpromazine, or placebo by oral administration. All the patients were administered by nalbuphine (5 $\mathrm{mg}$, intravenous). Both neuroleptics blocked the nalbuphine antianalgesia effect, resulting in enhanced analgesia (29). Ebneshahidi et al. selected 98 patients undergoing elective general, gynecologic or orthopedic surgery. The participants received either $2 \mathrm{mg}$ haloperidol or sterile water intravenously after the induction of anesthesia. The pain intensity and the demand for additional analgesic were measured in the sixth postoperative hour. They found that the pain scores in the haloperidol-treated patients were higher than the placebo group. This finding may be due to the low dose of haloperidol used (30).

The available evidences suggest the administration of haloperidol as an adjunct with morphine for postoperative pain management to be more beneficial than morphine alone, especially in addicted patients whose morphine consumption as a tranquillizer is more than normal. However, further studies are required on larger numbers of patients.

\section{Acknowledgments}

This paper was extracted from the thesis of Tahere Jowkar, medical student at Shiraz University of Medical Sciences with approval No. CT-87-3951. The thesis proposal was approved in May 2008. The authors would like to thank the patients and nurses of the Recovery Unit in Chamran Hospital, Shiraz, Iran.

\section{Authors' Contributions}

Study concept and design: Asif Parviz Kazemi. Acquisition of data: Tahere Jowkar, Asif Parviz Kazemi. Analysis and interpretation of data: Tahere Jowkar, Asif Parviz Kazemi. Drafting of the manuscript: Tahere Jowkar. Critical revision of the manuscript for important intellectual content: Asif Parviz Kazemi, Afshin Amini. Statistical analysis: Seyed Taghi Heydari. Administrative, technical, and material support: Asif Parviz Kazemi, Afshin Amini. Study supervision: Asif Parviz Kazemi, Afshin Amini.

\section{Funding/Support}

This paper was financially supported by the research deputy of Shiraz University of Medical Sciences.

\section{References}

1. Javid MJ, Ghanbar M, Shahidi A, Golbabaii SH, Atashkhoii S, Shahrokhi SH. Advantages of buprenorphine in comparison to morphine in postoperative pain control. Shiraz E Med J. 2008;9(3):129-33.

2. Imantalab V, Mirmansouri A, Sedighinejad A, Naderi Nabi B, Farzi $\mathrm{F}$, Atamanesh $\mathrm{H}$, et al. Comparing the effects of morphine sulfate and diclofenac suppositories on postoperative pain in coronary artery bypass graft patients. Anesth Pain Med. 2014;4(4):e19423.

3. Mao J, Sung B, Ji RR, Lim G. Chronic morphine induces downregulation of spinal glutamate transporters: implications in morphine tolerance and abnormal pain sensitivity. J Neurosci. 2002;22(18):8312-23.

4. Dahi-Taleghani M, Fazli B, Ghasemi M, Vosoughian M, Dabbagh A. Effect of intravenous patient controlled ketamine analgesiaon postoperative pain in opium abusers. Anesth Pain Med. 2014;4(1):e14129.

5. Imani F, Faiz HR, Sedaghat M, Hajiashrafi M. Effects of adding ketamine to fentanyl plus acetaminophen on postoperative pain by patient controlled analgesia in abdominal surgery. Anesth Pain Med. 2014;4(1):e12162.

6. Imani F, Rahimzadeh P, Faiz SH. Comparison of the efficacy of adding clonidine, chlorpromazine, promethazine, and midazolam to morphine pumps in postoperative pain control of addicted patients. Anesth Pain Med. 2011;1(1):10-4

7. Ebrahimzadeh $\mathrm{MH}$, Mousavi SK, Ashraf H, Abubakri R, Birjandinejad A. Transdermal fentanyl patches versus patient-controlled intravenous morphine analgesia for postoperative pain management. Iran Red Crescent Med J. 2014;16(5):e11502.

8. Lee RM, Lim Tey JB, Chua NH. Postoperative pain control for total knee arthroplasty: continuous femoral nerve block versus intravenous patient controlled analgesia. Anesth Pain Med. 2012;1(4):239-42.

9. Gutstein HB, Akil H. Opioid Analgesics. Opioid agonist/antagonist and partial agonists Goodman \& Gilman's-The pharmacological basis of therapeutics. 11 ed. Toronto:McGraw-Hill, Medical Publishing Division.; 2006. pp. 574-6.

10. Clay GA, Brougham LR. Haloperidol binding to an opiate receptor site. Biochem Pharmacol.1975;24(13-14):1363-7.

11. Creese I, Feinberg AP, Snyder SH. Butyrophenone influences on the opiate receptor. EurJPharmacol.1976;36(1):231-5. 
12. Lal H, Numan R. Blockade of morphine-withdrawal body shakes by haloperidol. Life Sci.1976;18(2):163-7.

13. Lal H, Puri S, Karkalas Y. Blockade of opioid-withdrawal symptoms by haloperidol in rats and humans. Pharmacologist. 1971;13(2):263.

14. Raft D, Toomey T, Gregg JM. Behavior modification and haloperidol in chronic facial pain. South Med J.1979;72(2):155-9.

15. Fishbain DA, Cutler RB, Lewis J, Cole B, Rosomoff RS, Rosomoff HL. Do the second-generation "atypical neuroleptics" have analgesic properties? A structured evidence-based review. Pain Med. 2004;5(4):359-65.

16. Seidel S, Aigner M, Ossege M, Pernicka E, Wildner B, Sycha T. Antipsychotics for acute and chronic pain in adults.J Pain Symptom Manage. 2010;39(4):768-78.

17. Hanks GW. Psychotropic drugs. Postgrad Med J.1984;60(710):881-5.

18. Patt RB, Proper G, Reddy S. The neuroleptics as adjuvant analgesics. J Pain Symptom Manage. 1994;9(7):446-53.

19. Head M, Lal H, Puri S, Mantione C, Valentino D. Enhancement of morphine analgesia after acute and chronic haloperidol. Life Sci. 1979;24(22):2037-43.

20. Rooney KF, Sewell RD. Evaluation of selective actions of dopamine D-1 and D-2 receptor agonists and antagonists on opioid antinociception. Eur J Pharmacol.1989;168(3):329-36.

21. Karkalas J, Lal H. A comparison of haloperidol with methadone in blocking heroin-withdrawal symptoms. A pilot study. Int Pharmacopsychiatry. 1973;8(4):248-51.
22. Karkalas Y, Lal H. Haloperidol In Treatment OfOpioid Addiction.New York, Ny: Clinical Toxicology; 1972. p. 10016.

23. Saarne A. Experiences with haloperidol (Haldol) as a premedicant. Acta Anaesthesiol Scand.1963;7:21-30.

24. Maltbie AA, Cavenar JJ, Sullivan JL, Hammett EB, Zung WW. Analgesia and haloperidol: a hypothesis. J Clin Psychiatry. 1979;40(7):323-6.

25. Judkins KC, Harmer M. Haloperidol as an adjunct analgesic in the management of postoperative pain. Anaesthesia.1982;37(11):1118-20.

26. Honkaniemi J, Liimatainen S, Rainesalo S, Sulavuori S. Haloperidol in the acute treatment of migraine: a randomized, double-blind, placebo-controlled study. Headache. 2006;46(5):781-7.

27. Hagelberg N, Jaaskelainen SK, Martikainen IK, Mansikka H, Forssell $\mathrm{H}$, Scheinin $\mathrm{H}$, et al. Striatal dopamine D2 receptors in modulation of pain in humans: a review. EurJ Pharmacol. 2004;500(1-3):187-92.

28. Hagelberg N, Martikainen IK, Mansikka H, Hinkka S, Nagren K, Hietala J, et al. Dopamine D2 receptor binding in the human brain is associated with the response to painful stimulation and pain modulatory capacity. Pain. 2002;99(1-2):273-9.

29. Gear RW, Lee JS, Miaskowski C, Gordon NC, Paul SM, Levine JD. Neuroleptics antagonize nalbuphine antianalgesia. J Pain. 2006;7(3):187-91.

30. Ebneshahidi A, Akbari M, Mohseni M. Intraoperative haloperidol does not improve quality of recovery and postoperative analgesia. Adv Biomed Res. 2013;2:85. 